\section{BOOK REVIEW}

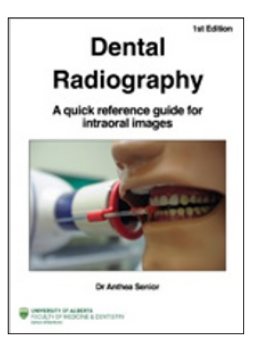

DENTAL RADIOGRAPHY (E-BOOK)

A. Senior

Available from the iBooks store

price $€ 5.49$

Apple ID: 910769832

With the majority of the popula-

tion now able to purchase books

for their tablet or mobile phone, there has been a massive trend towards dental textbooks being available in electronic form.

Dental radiography: A quick reference guide for intra-oral images by Dr Anthea Senior, Clinical Associate Professor in Dental Radiology from the University of Alberta, is only available in e-book format (only from the Apple iBook at present.) This 49 page e-book has been produced with the aim of providing tips on radiography for intra-oral views for newly qualified dentists or anyone new to using digital radiography.

The book starts with an introduction covering patient preparation, what anatomical landmarks should be seen on the radiographs and rectangular collimation. In the section on patient protection, there is a good section on regulations for radiation protection. Even though this book has been primarily written with the Canadian and American market in mind, the majority of this information is still correct to be in keeping with the UK regulations, IR(ME)R.

The next chapter is on the techniques for taking diagnostic intra-oral views. This includes bitewings, periapicals, bisecting angles and occlusals. The theory behind these techniques is well written in bullet points making it easy to read and this is supplemented by multiple photos, diagrams and video clips. There is mention of Canadian Radiation safety codes in this section which are not applicable for the UK. Within this chapter, there is a section on intra-oral techniques for children. Unfortunately, some of these recommendations, particularly the use of full mouth periapicals with supplemental bitewings, are not in keeping with the FGDP Selection Criteria Guidelines for the UK.

The last chapter of this e-book contains tricks and tips for difficult patients or anatomy, such as unusually long roots and strong gag reflexes. It also has a slide show on radiographic errors, which has multiple examples of various errors that can occur with intra-oral views.

In summary, this is a useful reference guide (particularly chapter two, Intra-oral techniques) that you could have close to hand if you notice that you are having problems acquiring diagnostic intraoral radiographs, or if your clinic has just changed to using direct digital or indirect digital phosphor plates. Unfortunately, some of the selection criteria and regulations included in this e-book are not relevant for the UK so some caution should be taken in relation to this.

K. DONALDSON

\title{
HOW BADLY MUST A REGULATOR PERFORM BEFORE SOMEONE INTERVENES, ASKS BDA
}

The British Dental Association (BDA) is concerned that the General Dental Council (GDC) has come bottom of the league in an assessment of the performance of nine healthcare regulators, published recently by the Professional Standards Authority (PSA).

The PSA highlights that the GDC failed to meet a total of seven of its standards of good regulation.

On fitness to practise, the GDC fully met only one of the 10 standards, and failed to meet six others, representing what the PSA describes as a significant decline in its performance compared to an assessment it carried out in 2013/14.

The BDA notes that the jury couldn't decide on whether the GDC had met two additional standards on fitness to practise pending an ongoing enquiry by the PSA.

The PSA has yet to comment on whether it considers the GDC's activities in this area are 'transparent, fair, proportionate and focused on public protection'.
Commenting on the PSA report, BDA Chair Mick Armstrong, said: 'Sadly this report makes familiar reading. Yet again GDC registrants must acknowledge that they are being regulated by the worst health regulator in the UK. What is worse is that, as far as dentists are concerned, it is now also the most expensive by a country mile.

'The findings in relation to fitness to practise come as little surprise as stories of waste, mismanagement and unreasonable practices abound.

'It is difficult to understand how badly the GDC has to perform before someone actually intervenes.'

Responding to the review, the GDC said: ‘Today's PSA report confirms that in the areas of guidance and standards, education and training, and registration the GDC is performing well. However, we also recognise that the PSA has identified a number of areas within the fitness to practise (FtP) category where reform is required.

\section{PAINKILLERS BEFORE ORAL SURGERY FAIL TO ENSURE RELIEF}

Giving drugs before surgery to reduce postoperative pain is nothing new. Using drugs before surgery to reduce the use of painkillers could be highly desirable. But does it work?

The authors of an article published in the current issue of the journal Anesthesia Progress discovered there is no benefit from the pre-operative use of ibuprofen and similar drugs in decreasing postoperative pain.

Dentists often prescribe oral drugs for post-operative pain. Non-steroidal anti-inflammatory drugs (NSAIDs) such as ibuprofen are a popular option worldwide because they are common, cheap, and effective. When painkillers are given before surgery, they ideally reduce - or even prevent - the pain that is typically felt during and after an operation. When these drugs work, patients recover faster and get back to their daily activities more quickly.

In the studies, over-the-counter medications such as ibuprofen were given before oral surgery in an attempt to cut down prescription painkiller use afterward. The authors hoped that by systematically reviewing existing research, they could find out whether such pre-emptive efforts work.

The studies reported that giving ibuprofen before or after surgery resulted in the same levels of pain, facial edema, and limited mouth opening. Ketoprofen, another NSAID, was given at different dosages before surgery in different studies, but the results were the same.

The authors found it impossible to draw stronger conclusions because the timing, types of drugs and surgery, and use of other pain relief techniques varied so widely among the studies. They concluded that further careful clinical trials are required to provide solid information on this controversial topic. 